\title{
Implementation of Fuzzy Logic in Determining the Value of Uncertainty Factors on Expert System
}

\author{
Rusdi EFENDI ${ }^{1}$, YUNITA $^{2}$, M. Ihsan JAMBAK ${ }^{3}$, Leny MARLINA ${ }^{4}$ \\ ${ }^{1}$ rusdie@ unsri.ac.id Programme of Study in Informatics Management Faculty of computer science Sriwijaya \\ University \\ ${ }^{2}$ yunita.v1t4@gmail.com Department of Informatics engineering Faculty of computer science Sriwijaya University \\ 3 jambak@ilkom.unsri.ac.id Programme of Study in Informatics Management Faculty of computer science Sriwijaya \\ University \\ ${ }^{4}$ lenymarlina8@gmail.com Faculty of tarbiyah and Teacher Training Raden Fatah State Islamic University
}

\begin{abstract}
An intelligent system is a system that was built by imitating the ability of an expert in solving problems encountered. To adopt the ability of an expert in the system set forth in the form of rules that are usually in the form of IF ... Then rules. Each rule usually has a uncertainty value to declare the end result. This value is obtained from experts who are a combination of many rules that exist in knowledge-based systems but sometimes to get the uncertainty value is very difficult because the understanding is not the same between experts and system developers and the measurement of the uncertainty value itself is not easy, so to overcome the problem The researcher tried to combine the use of the fuzzy method in the expert system. Where the input from the uncertainty value of this system is fuzzy linguistic such as: rarely, sometimes, often etc., then the calculation process uses the certainty factor $(C F)$ method. The final results of this study are expected to provide convenience in measuring the uncertainty value in the expert system so that it is easier to do the analysis.
\end{abstract}

Keywords: expert system, fuzzy method, certainty factor method

\section{Introduction}

People who have never known fuzzy logic will surely think that fuzzy logic is something that is very complicated and unpleasant. However, once someone starts getting to know him, he will definitely be very interested and will become a newcomer to participate in learning fuzzy logic. The fuzzy set initially tries to solve the problem in the crisp set, because the degree of membership of a number in the crisp set is usually if it is one (1), which means that an item becomes a member in a set, or zero (0), which means that an item does not become a member in a set, whereas in fuzzy numbers a number has a membership value between 0 and 1 . Usually these fuzzy representations are also often written in the form: often, sometimes, rarely, etc.

The implementation of fuzzy logic has been widely used in various fields, including in various other fields of science such as expert systems. The expert system is a branch of science that makes special extensions to specialized knowledge in order to solve a problem at the expert level. The most common form of expert system is the expert system for diagnosing diseases. In the expert system to make a decision rule often found answers that do not have full certainty. This uncertainty can be a probability or probability that depends on the outcome of an event. Uncertain results are caused by two factors, namely uncertain rules and uncertain user answers to questions raised by the system [1].
To overcome this in an expert system, several algorithms are used to calculate the uncertainty value. The methods used in the expert system include; Certainty Factor, Bayes, Dempster Shafer[2]. For example: if a patient has a fever and spots then the patient suffers from smallpox with an uncertainty value: $80 \%$, if a rule is made in the expert system, then the form becomes: "IF the patient has a fever and then smallpox spots with CF: 0.8 ". But sometimes to get the uncertainty value in the rule above (80\%) sometimes the understanding between experts and us is not the same. So from the experience that occurs when we or students take the final assignment about an expert system, what happens is that the uncertainty value entered into the rule in the system is not the original value of the expert but many are the result of engineering.

To overcome this, the authors took the initiative to apply the fuzzy logic method which was hybridized with the certainty factor method. In this method, each rule is not included with the uncertainty value as in the example rule above, but it is enough to fill the intensity level of each symptom of the disease by using fuzzy linguistic words, for example: to determine the frequency of symptoms that appear frequently use the word: often, sometimes, or never. Then the value of the answers given will be processed so that it will produce an uncertainty value using the certainty factor $(\mathrm{CF})$ method. This method is better because in the calculation process it can only perform two data calculations in one process so that the accuracy of the data can be maintained. Thus it is expected that the results of 
this method can replace the uncertainty value given by the expert. The case domain that will be examined is regarding child development disorders.

\section{RESEARCH METHODOLODY}

The following is a general description of the expert system that will be built as shown in the following figure:

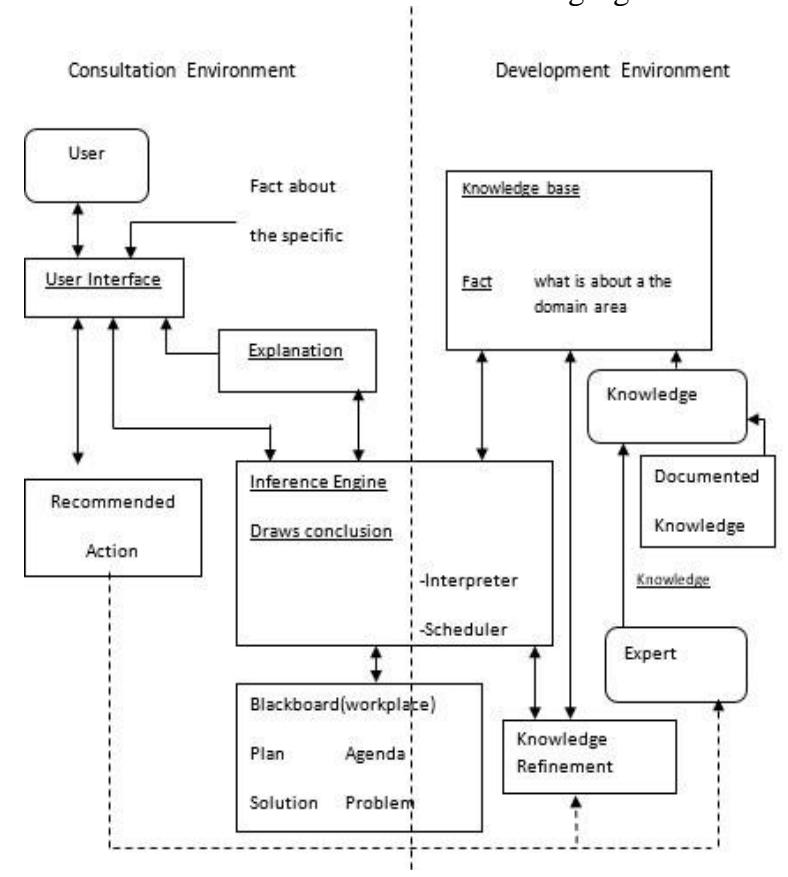

Figure 1. Expert System Components

The expert system is a branch of Artificial Intelligence (AI) that makes special extensions to specialized knowledge in order to solve a problem at the Humam Expert level. Humam Expert is someone who is an expert in a particular field of science, this means that the Expert has a special knowledge or skill that is not owned by anyone else. Expert can solve problems that cannot be solved by others in an efficient way [3].

Knowledge in expert systems may come from other people, or knowledge from reference books, newspapers, or other people's scientific writing. In general, an expert system (expert system) is a system that seeks to adopt human knowledge to a computer so that the computer can solve problems as is usually done by experts. Expert systems are designed to be able to solve a particular problem by imitating the work of experts.

The main purpose of an expert system is not to replace the position of an expert, but only to popularize the knowledge and experience of the experts. As human population grows, in the future this expert system is expected to be very useful in assisting in decision making. The expert system consists of several main parts, namely [4]:

\section{Knowledge Acquisition Facility}

Knowledge acquisition is the accumulation and transformation of expertise. Problem solving from sources of knowledge to software to create or develop a basic knowledge base of knowledge about domains including basic terms and concepts. Expert knowledge is contained in books, journals and so on. However, not all expertise can be documented. Interactive procedures are needed to get additional information from experts in developing basic knowledge. This process is quite complex and usually requires the help of engineering knowledge. The knowledge base contains the knowledge needed to understand, formulate and solve problems. Problem solving knowledge base in a particular domain and facts about a problem. Sources of knowledge can include human experts, books, databases, research reports, or images. Information in the knowledge base must be stated in the form of a certain knowledge representation so that it can be used by the inference engine.

\section{Inference Engine}

The inference engine functions to trace the knowledge contained in the knowledge base to reach certain conclusions. The inference engine provides direction on how to use system knowledge in building agendas that organize and control the steps taken to solve problems during consultations. There are 3 main elements in the inference engine, namely:

Interpreter ; Execute selected agenda items by using rules in the appropriate knowledge base

Scheduler ; This component will control the agenda to be worked on

Consistency enforce ; This component aims to maintain consistency in presenting solutions that are emergency.

The inference engine itself will use two methods; fuzzy logic and certainty factor

\section{Certainty Factor (CF)}

Certainty Factor $(\mathrm{CF})$ shows the measure of certainty of a fact or rule. The Certainty Factor Notation is as follows: $\mathbf{C F}[\mathrm{h}, \mathrm{e}]=\mathrm{MB}[\mathrm{h}, \mathrm{e}]-\mathrm{MD}[\mathrm{h}, \mathrm{e}]$

with :

$\mathrm{CF}[\mathrm{h}, \mathrm{e}]$ : Certainty factor

$\mathrm{MB}[\mathrm{h}, \mathrm{e}]:$ measure of confidence in hypothesis $\mathrm{h}$, if given evidence e (between 0 and 1). MD[h,e] : measure of mistrust of evidence $\mathrm{h}$, if given evidence e (between 0 and 1)

According to Heckerman the MYCIN Method Combination for combining evidence in antecedents of a rule is shown in the following table[5]: 


\begin{tabular}{|c|c|}
\hline Evidence & Antecedent \\
\hline E1 and E2 & $\min [\mathrm{CF}(\mathrm{H}, \mathrm{E} 1), \mathrm{CF}(\mathrm{H}, \mathrm{E} 2)$ \\
\hline E1 or E2 & $\max [\mathrm{CF}(\mathrm{H}, \mathrm{E} 1), \mathrm{CF}(\mathrm{H}, \mathrm{E} 2)$ \\
\hline Not E & $-\mathrm{CF}(\mathrm{H}, \mathrm{E})$ \\
\hline
\end{tabular}

The formula rules in table (1) above are used in the antecedents of those in the expert system, whereas if in a basic rule, the certainty factor formula for a rule" IF E THEN H" is as follows :

$\mathrm{CF}(\mathrm{H}, \mathrm{e})=\mathrm{CF}(\mathrm{E}, \mathrm{e}) * \mathrm{CF}(\mathrm{H}, \mathrm{E})$

with :

$\mathrm{CF}(\mathrm{E}, \mathrm{e})$ : Certainty Factor E evidence that is influenced by evidence $\mathrm{e}$

$\mathrm{CF}(\mathrm{H}, \mathrm{E})$ : Certainty Factor hypothesis with the assumption of evidence is known with certainty, namely when $\mathrm{CF}(\mathrm{E}, \mathrm{e})$ $=1$

$\mathrm{CF}(\mathrm{H}, \mathrm{e})$ : Certainty Factor hypothesis which is influenced by evidence e

The rules of formula (2) above are usually used if the rules in an expert rule system with a single rule, but for rules consisting of several premises connected by AND or OR will use the formula for determining the value of certainty factors with several rules that refer to a hypothesis that same. Usually this formula is called the "rule of combination of $\mathrm{CF}^{\prime \prime}$ formula, as shown in formula (3) below:

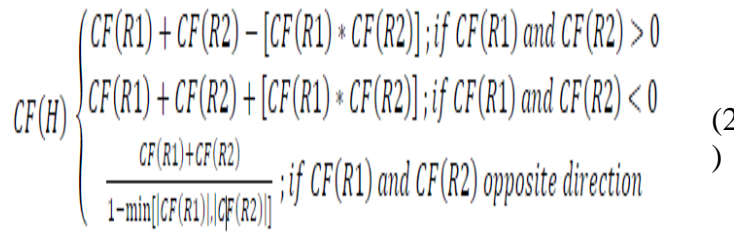

\section{Fuzzy Logic}

Fuzzy logic is an appropriate way to map an input space into an output space. In a firm set (crisp), the membership value of item $\mathrm{x}$ in a set $\mathrm{A}$, which is often written as $\mu \mathrm{A}[\mathrm{x}]$, has 2 possibilities, namely:

one (1), which means that an item is a member in a set, or

zero $(0)$, which means that an item does not belong to a set.

For example the age variable is divided into 3 categories, namely: YOUNG age $<35$ years

Middle age $\quad 35 \geq$ age $\leq 55$ years

OLD age $>55$ years

Graphically membership values, the set of YOUNG, Middle and OLD can be seen in Figure 2 following :

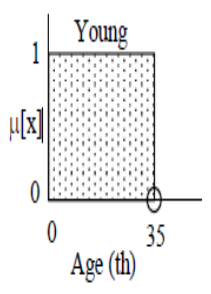

(a)

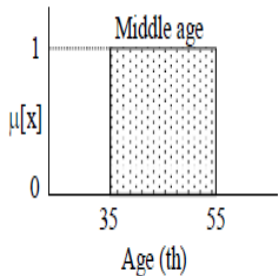

(b)

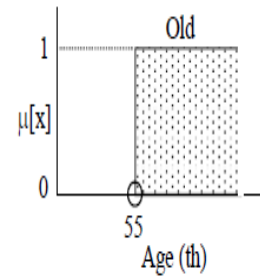

(c)
Figure 2. Set: YOUNG, middle, and OLD.

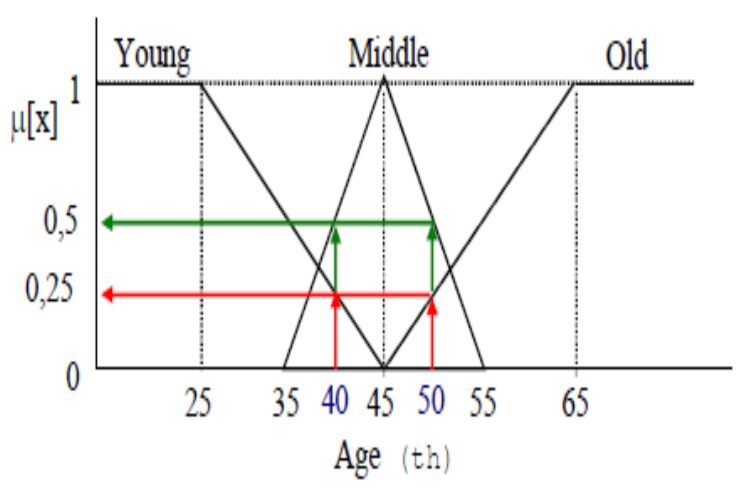

Figure 3. Fuzzy set for the Age variable.

In Figure 3, it can be seen that:

Someone who is 40 years old, belongs to the YOUNG set up with YOUNG [40] $=0.25$; but he is also included in the set middle age with middle age [40] $=0.5$.

Someone who is 50 years old, belongs to the YOUNG set up with $\mu$ OLD [50] $=0.25$; but he is also included in the set middle age with middle age [50] $=0.5$.

If on the crisp set, the membership value is only 2 possibilities, namely 0 or 1 , in the fuzzy set the membership value lies in the range 0 to 1 . If $\mathrm{x}$ has a fuzzy membership value $\mu \mathrm{A}[\mathrm{x}]=0$ means $\mathrm{x}$ does not belong to the set $\mathrm{A}$, similarly if $x$ has fuzzy membership value $A[x]=1$, it means that $\mathrm{x}$ is a full member of the set $\mathrm{A}$.

\section{Blackboard}

Blackboard is an area of working memory that is used to describe problems and record temporary results before getting the final solution. Three types of decisions that can be stored on a blackboard are plans, agendas, and solutions. Plan is how to solve the problem. Agenda namely: potential action awaiting execution. The solution is: candidate hypothesis and alternative ways of action that have been raised by the system. 


\section{User Interface}

The user interface is used to facilitate communication between users and the system. Such communication includes requests for information needed by the system to find solutions, sharing information from users, providing information from users to the system, requesting explanatory information from users to the system, requesting explanatory information by users, and providing information by the system.

\section{Explanation Facility}

Explanation facilities help engineering knowledge to improve and enhance knowledge and provide clarity and confidence to users about the process or results provided by expert systems. This facility is used to track responses and provide an explanation of the behavior of the expert system interactively through questions:

Why a question is asked by an expert system

How conclusions are achieved

Why are alternatives canceled

What plans will be used to reach a solution

\section{Knowledge Improvement Facilities}

Human experts can analyze their own performance, learn from them, and improve them for the next consultation. An evaluation with this expert system will result in a better knowledge base and more effective reasoning.

\section{DISCUSSION}

The first process that will be carried out in building an expert system is the process of getting knowledge that will become a knowledge based system, a process like this is better known as knowledge acquisition. Basically an expert system is transferred from an expert to a computer, existing knowledge is stored in a computer, and the user can consult on that computer for advice, then the computer can take inferences (deduce, deduce, etc.) like an expert, then explain it to these users, if necessary for their reasons. This knowledge acquisition process is carried out by conducting literature studies and interviews.

After the knowledge acquisition process is completed, the knowledge must be presented into a knowledge base and a rule base that is subsequently collected, coded, organized and illustrated in other design forms into a systematic form. There are several ways to represent data into a basis of knowledge, namely in the form of attributes, rules, semantic networks, frames, logic and production rules. All forms of data representation aim to simplify the data so that it is easy to understand and make the program development process effective. As for the representation of knowledge in the expert system of diagnosing parasitism is to use a decision table that will produce a rule of production [6].Decision tables are knowledge organized in a spreadsheet format, using columns and rows. The table is divided into two parts, the first part is a list of attributes where each attribute is listed in value, the second part is a conclusion where the configuration of different attributes is adjusted to the conclusion.

Table 2. Decision table for diagnosing animal parasitism

\begin{tabular}{|c|c|c|c|c|c|c|}
\hline $\begin{array}{l}\text { Diagnosis } \\
\text { Evidence }\end{array}$ & $\begin{array}{c}\text { Endo } \\
\text { parasitisme } \\
\text { Fascoliasis }\end{array}$ & $\begin{array}{l}\text { Endo } \\
\text { parasitisme } \\
\text { Ascariasis }\end{array}$ & $\begin{array}{l}\text { Endo } \\
\text { parasitisme } \\
\text { Haemon- } \\
\text { Chosis }\end{array}$ & $\begin{array}{l}\text { Endo } \\
\text { parasitisme } \\
\text { Bunosto- } \\
\text { miasis }\end{array}$ & $\begin{array}{c}\text { Endo } \\
\text { parasitisme } \\
\text { Strongy- loides }\end{array}$ & $\begin{array}{c}\text { Endo parasitisme } \\
\text { Oesophagos- } \\
\text { tomum spp }\end{array}$ \\
\hline Ax, Ay & $\sqrt{ }$ & $\sqrt{ }$ & $\sqrt{ }$ & $\sqrt{ }$ & V & $\sqrt{ }$ \\
\hline $\mathrm{B}$ & $\sqrt{ }$ & $\sqrt{ }$ & $\sqrt{ }$ & $\sqrt{ }$ & $\sqrt{ }$ & $\sqrt{ }$ \\
\hline $\mathrm{C}$ & $\sqrt{ }$ & $\sqrt{ }$ & $\sqrt{ }$ & $\sqrt{ }$ & V & $\sqrt{ }$ \\
\hline $\mathrm{D}$ & $\sqrt{ }$ & $\sqrt{ }$ & $\sqrt{ }$ & $\sqrt{ }$ & V & $\sqrt{ }$ \\
\hline $\mathrm{E}$ & $\sqrt{ }$ & $\sqrt{ }$ & $\sqrt{ }$ & $\sqrt{ }$ & V & $\sqrt{ }$ \\
\hline $\mathrm{F}$ & $\sqrt{ }$ & $\sqrt{ }$ & $\sqrt{ }$ & $\sqrt{ }$ & V & $\sqrt{ }$ \\
\hline G & $\sqrt{ }$ & $\sqrt{ }$ & $\sqrt{ }$ & $\sqrt{ }$ & V & $\sqrt{ }$ \\
\hline $\mathrm{H}$ & $\sqrt{ }$ & $\sqrt{ }$ & $\sqrt{ }$ & $\sqrt{ }$ & V & $\sqrt{ }$ \\
\hline I & $\sqrt{ }$ & $\sqrt{ }$ & $\sqrt{ }$ & $\sqrt{ }$ & V & $\sqrt{ }$ \\
\hline $\begin{array}{l}\mathrm{J} 1, \mathrm{~J} 2, \mathrm{~J} 3, \mathrm{~J} 4, \mathrm{~J} 5, \mathrm{~J} \\
6, \mathrm{~J} 7, \mathrm{~J} 8, \mathrm{~J} 9, \mathrm{~J} 10\end{array}$ & $\sqrt{ }$ & - & - & - & - & - \\
\hline $\begin{array}{c}\mathrm{K} 1, \mathrm{~K} 2, \mathrm{~K} 3, \mathrm{~K} 4, \\
\mathrm{~K} 5, \mathrm{~K} 6\end{array}$ & - & $\sqrt{ }$ & - & - & - & - \\
\hline \begin{tabular}{|c|}
$\mathrm{L} 1, \mathrm{~L} 2, \mathrm{~L} 3, \mathrm{~L} 4, \mathrm{~L}$ \\
$5, \mathrm{~L} 6, \mathrm{~L} 7$
\end{tabular} & - & - & $\sqrt{ }$ & - & - & - \\
\hline $\begin{array}{c}\mathrm{M} 1, \mathrm{M} 2, \mathrm{M} 3, \\
\mathrm{M} 4\end{array}$ & - & - & - & $\sqrt{ }$ & - & - \\
\hline $\begin{array}{c}\text { N1,N2,N3,N4, } \\
\text { N5,N6,N7 }\end{array}$ & - & - & - & - & V & - \\
\hline $\begin{array}{c}\mathrm{O} 1, \mathrm{O} 2, \mathrm{O} 3, \mathrm{O} 4, \\
\mathrm{O} 5, \mathrm{O} 6\end{array}$ & - & - & - & - & - & $\sqrt{ }$ \\
\hline
\end{tabular}


Note :

$\mathrm{Ax}=$ young age $\mathrm{Ay}=$ adulthood $\mathrm{B}=$ anemia

$\mathrm{C}=$ growth disturbance $\mathrm{D}=$ weight loss

$\mathrm{E}=$ decreased appetite

$\mathrm{F}=$ grass feed from wet areas $\mathrm{G}=$ kept in groups

$\mathrm{H}=$ stress

$\mathrm{I}=$ symptom factor of gastrointestinal endoparasitism $\mathrm{J} 1=$ egg fascioliasis

$\mathrm{J} 2=$ abnormal liver function

$\mathrm{J} 3=$ bleeding in the peritoneal cavity $\mathrm{J} 4=$ abnormalities in the bile duct

$\mathrm{J} 5=$ diare

$\mathrm{J} 6=$ impaired fat metabolism $\mathrm{J} 7=$ looks listless

$\mathrm{J} 8=$ abnormalities of the circulatory system in the heart J9 $=$ oxidation mixed with blood in the nostrils

$\mathrm{J} 10$ = oxidation mixed with blood in the anal canal $\mathrm{K} 1=$ egg ascariasis

$\mathrm{K} 2$ = spewing adult ascariasis worms $\mathrm{K} 3=$ rapid and shallow breathing

K4 = decreased intestinal motility K5 = Feces mixed with fat

$\mathrm{K} 6=$ eosinophilia found in the blood L1 = Haemonchosis worm egg

L2 $=$ There are a number of worms in the mucosa L3 = accumulation of fluid in the body cavity

L4 = Deodenum in the upper part is thickening L5 = Sub mucosal tissue is bleeding

L6 = Mucosa looks pale

L7 = dehydration in body tissues M1 = Bunostomiasis worm egg M2 = itching of the feet

M3 = inflammation of the small intestine M4 = abnormalities in submandibular edema N1 = Strongyloides worm eggs

$\mathrm{N} 2$ = coughing

$\mathrm{N} 3=$ inflammation of the lungs N4 = paleness

$\mathrm{N} 5=$ inflammation of the intestine N6 = lameness in the legs

N7 = dermatitis on the skin $\mathrm{O} 1=$ Oesophagostomum spp

$\mathrm{O} 2=$ abnormality in the colon in the form of pus-filled nodules $\mathrm{O} 3$ = experiencing muscle atrophy

$\mathrm{O} 4=$ unable to stand again $\mathrm{O} 5=$ Feathers look dull

O6 $=$ thickening of the intestinal mucosa covered by slimy detritus

Representation of the rules of production is how existing knowledge is presented as a rule of production in the form of action, ie IF pairs of conditions (premise or antacedent) occur THEN actions (conclusions or conclusions). This rule is arranged according to the tree and the decision table above, so as to diagnose gastrointestinal endoparasitism, a set of rules is obtained as follows:

A. Factors for Symptoms of Gastrointestinal Endoparasitism Rule 1

IF Your animal is young

THEN suffers from Gastrointestinal Endoparasitism (Mrule $=0.1)$ Rule 2

IF Your animal is mature

THEN suffers from Gastrointestinal Endoparasitism (Mrule $=0.05)$ Rule 3

IF Your animal has mild anemia

THEN suffers from Gastrointestinal Endoparasitism $($ Mrule $=0.3)$ Rule 4

IF Your animal has severe anemia

THEN suffers from Gastrointestinal Endoparasitism $($ Mrule $=0.5)$ Rule 5
IF Your animal has a growth disorder

THEN suffers from Gastrointestinal Endoparasitism $($ Mrule $=0.25)$ Rule 6

IF Your animal has lost less than $3 \mathrm{~kg}$

THEN suffers from Gastrointestinal Endoparasitism (Mrule $=0.05$ ) Rule 7

IF Your animal has a weight loss of $3-5 \mathrm{~kg}$

THEN suffers from Gastrointestinal Endoparasitism $($ Mrule $=0.1)$ Rule 8

IF Your animal has lost more than $5 \mathrm{~kg}$

And so on until all diseases are covered by all the rules that represent them

The next stage is the inference process by using fuzzy logic and certainty factors. Rule-rules containing fuzzy values will be carried out by the fuzzification process to get the value of the degree of membership of each symptom. For example weight loss in animals can be divided into: low, medium and high with an input value of all symptoms between 1 to 5 , then you will get a membership function curve with the following formula :

$$
\begin{aligned}
& \mu_{\text {low }}[x]=\left\{\begin{array}{c}
1 ; x \leq 1 \\
\frac{3-x}{3-1} ; 1 \leq x \leq 3 \\
0 ; x \geq 3
\end{array}\right. \\
& \mu_{\text {medium }}[x]=\left\{\begin{array}{c}
0 ; x \leq 1 \text { or } x \geq 5 \\
\frac{x-1}{3-1} ; 1 \leq x \leq 3 \\
\frac{5-x}{5-3} ; 3 \geq x \leq 5
\end{array}\right.
\end{aligned}
$$

$$
\mu_{\text {hight }}[x]=\left\{\begin{array}{c}
0 ; x \leq 3 \\
\frac{x-3}{5-3} ; 3 \leq x \leq 5 \\
1 ; x \geq 5
\end{array}\right.
$$

The membership value of each symptom will be multiplied by the trust value of the expert and then summed to get the trust value that will be used in the centainty factor calculation method. For example suppose from the calculation above, the $\mathrm{CF}$ value for animals experiencing moderate weight loss is:

0.63 and the second symptom appears, namely animals experiencing mild growth disturbance with a $\mathrm{CF}$ value of 0.48 .

From these two values, you will get the combination $\mathrm{CF}$ value according to formula (2) above where both $\mathrm{CF}$ values both $\mathrm{R} 1$ and $\mathrm{R} 2$ are positive, you will get the results: $\mathrm{CF}(\mathrm{H})=\mathrm{CF}(\mathrm{R} 1)+\mathrm{CF}(\mathrm{R} 2)-\left[\mathrm{CF}(\mathrm{R} 1)^{*} \mathrm{CF}(\mathrm{R} 2)\right] \mathrm{CF}(\mathrm{H})=$ $0,48+0,63-[0,48 * 0,63]$

$\mathrm{CF}(\mathrm{H})=0,808$

This means that the value of confidence in the emergence of the disease in the case above is equal: $80,8 \%$ 
[3]. Kusumadewi, S., Hartati, S., Harjoko, A., \& Wardoyo, R. (2006). Fuzzy Multi-Attribute Decision Making (FUZZY MADM). Graha Ilmu, Yogyakarta

Based on the above research results it can be concluded that the implementation of the fuzzy logic method in determining the uncertainty value of certainty factors in an intelligent system can be used especially for a rule that has fuzzy linguistic values such as: low, medium and high.

\section{REFERENCES}

[1]. Setyoningsih. W, 2015, "Application of Fuzzy Logic in Scheduling Lecture Time", UPGRIS Informatics Journal.

[2]. Judea Pearl, 2010, "Probabilistic Reasoning in Intelligent Systems", Morgan Kaufmann Publishers, San Mateo California, USA
[4]. Kusumadewi, Sri, 2009, "Artificial Intelligence (Engineering and Application)", Graha Science, Yogyakarta

[5]. Heckerman, D., 2010, "Probabilistic Interpretations for Mycin's Certainty Factors", Elsivier Science Publishers B.V, North-Holland

[6]. Risyanto.F, 2017, "Implementation of Fuzzy Logic Method and Demster Shafer Determination of Types of Developmental Disorders in Children", National Electronic Journal of Technology and Computer Science 